\title{
Health status and psychological distress among in-hospital cardiac arrest survivors in relation to sex
}

Johan Israelsson $1,2,3$, Anders Bremer ${ }^{1,4}$, Johan Herlitz ${ }^{4}$, Kristofer Årestedt ${ }^{1,3,5,6}$ - The PROM reference-group for the Swedish Register of Cardiopulmonary Resuscitation Kalmar County Hospital, Sweden ${ }^{1}$, Kalmar Maritime Academy, Linnaeus University, Sweden², Department of Medical and Health Sciences, Linköping University, Sweden ${ }^{3}$, Department of Acute and Prehospital Care and Medical Technology, and PreHospen - Centre for Prehospital Research, University of Borås, Sweden ${ }^{4}$,

Department of Health and Caring Science, Linnaeus University, Sweden ${ }^{5}$, Department of Health Care Science, Ersta Sköndal University College, Sweden ${ }^{6}$

Introduction \& Aim: Knowledge about health among cardiac arrest (CA) survivors is sparse, in particular among those suffering in-hospital cardiac arrest (IHCA). The aim was to describe health status and psychological distress among IHCA survivors in relation to sex.

\section{Methods: This nationa} register study presents follow-up data of 594 IHCA survivors, from $64 \%$ of eligible hospitals in Sweden, between 2013 and 2105. A questionnaire was sent to the survivors, 3-6 months post $C A$, including measures of health status (EQ-5D) and psychological distress (HADS).

No conflict of interest

For information mail to: Johan Israelsson Swedish Resuscitation Council johani@ltkalmar.se

\section{HLR $\$ rådet}

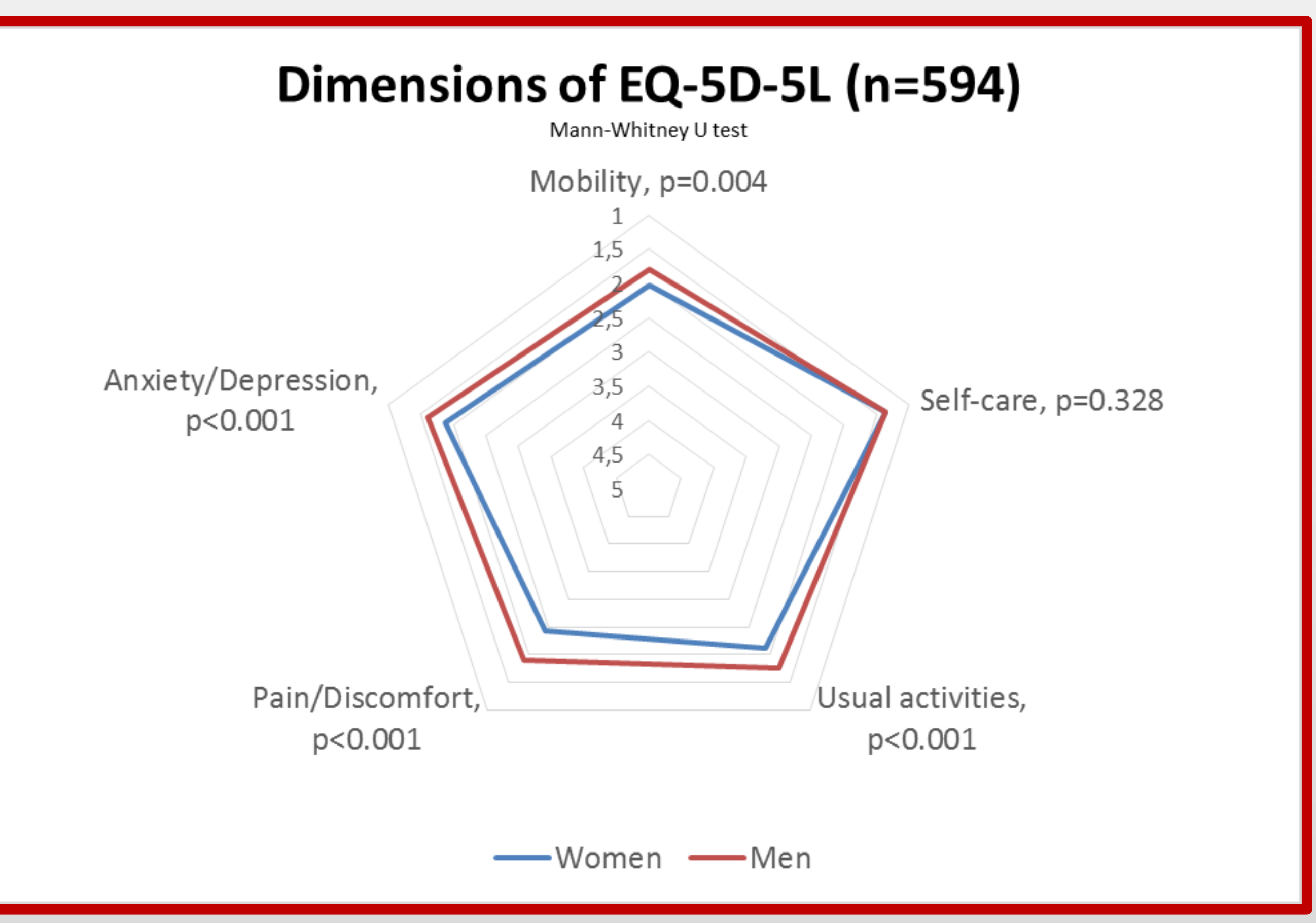

\begin{tabular}{|c|c|c|c|c|}
\hline \multicolumn{5}{|c|}{ Health status and psychological distress in relation to sex } \\
\hline Variable & $\begin{array}{l}\text { All patients } \\
\quad(n=594)\end{array}$ & $\begin{array}{l}\text { Women } \\
(n=218)\end{array}$ & $\begin{array}{c}\text { Men } \\
(n=376)\end{array}$ & $\mathrm{p}$-value \\
\hline EQ VAS, md (q1-q3) & $70(50-80)$ & $65(50-80)$ & $75(55-80)$ & $<0.001^{\mathrm{a}}$ \\
\hline EQ index, md (q1-q3) & $0.78(0.67-0.86)$ & $0.75(0.61-0.81)$ & $0.79(0.69-0.87)$ & $<0.001^{\mathrm{a}}$ \\
\hline HADS anxiety, md (q1-q3) & $2(0-5)$ & $3(1-6)$ & $2(0-5)$ & $<0.001^{\mathrm{a}}$ \\
\hline HADS depression, md (q1-q3) & $2(1-5)$ & $3(1-6)$ & $2(1-4)$ & $<0.001^{\mathrm{a}}$ \\
\hline
\end{tabular}

Results: Women reported more problems in most dimensions of EQ$5 \mathrm{D}$, worse health status (EQ-index) ( 0.75 vs $0.79, p<0.001$ ) and a lower median value for EQ-VAS ( 65 vs 75 , $p<0.001$ ). Women also reported more problems with anxiety and symptoms of depression compared to men. Being women was significantly associated with lower health status and more psychological distress in the regression models. No interaction effects for sex and age were found.

Conclusions: Although the majority of the survivors reported acceptable health status and no psychological distress, a substantial group reported serious problems. Women reported worse health status and more psychological distress compared to men. All IHCA survivors should be screened for health problems during the post cardiac arrest follow-up, and offered support when needed.
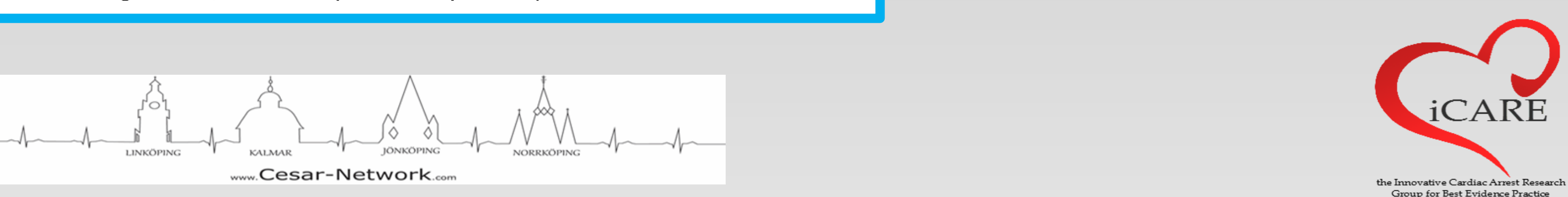